\title{
Climate Change Impact on Photovoltaic Energy Output: The Case of Greece
}

\author{
Ioanna S. Panagea, ${ }^{1}$ Ioannis K. Tsanis, ${ }^{1,2}$ \\ Aristeidis G. Koutroulis, ${ }^{1}$ and Manolis G. Grillakis ${ }^{1}$ \\ ${ }^{1}$ Department of Environmental Engineering, Technical University of Crete, GR73100 Chania, Greece \\ ${ }^{2}$ Department of Civil Engineering, McMaster University, Hamilton, ON, Canada L8S 4 L7 \\ Correspondence should be addressed to Ioannis K. Tsanis; tsanis@hydromech.gr
}

Received 4 April 2014; Revised 6 June 2014; Accepted 9 June 2014; Published 2 July 2014

Academic Editor: Huei-Ping Huang

Copyright (C) 2014 Ioanna S. Panagea et al. This is an open access article distributed under the Creative Commons Attribution License, which permits unrestricted use, distribution, and reproduction in any medium, provided the original work is properly cited.

Solar power is the third major renewable energy, constituting an increasingly important component of global future-low carbonenergy portfolio. Accurate climate information is essential for the conditions of solar energy production, maximization, and stable regulation and planning. Climate change impacts on energy output projections are thus of crucial importance. In this study the effect of projected changes in irradiance and temperature on the performance of photovoltaic systems in Greece is examined. Climate projections were obtained from 5 regional climate models (RCMs) under the A1B emissions scenario, for two future periods. The RCM data present systematic errors against observed values, resulting in the need of bias adjustment. The projected change in photovoltaic energy output was then estimated, considering changes in temperature and insolation. The spatiotemporal analysis indicates significant increase in mean annual temperature (up to $3.5^{\circ} \mathrm{C}$ ) and mean total radiation (up to $5 \mathrm{~W} / \mathrm{m}^{2}$ ) by 2100 . The performance of photovoltaic systems exhibits a negative linear dependence on the projected temperature increase which is outweighed by the expected increase of total radiation resulting in an up to $4 \%$ increase in energy output.

\section{Introduction}

Solar photovoltaic systems have largely penetrated the global energy market and especially Europe. According to the European Photovoltaic Industry Association [1], photovoltaics (PV) for second consecutive year is the dominant new source of electricity production installed in Europe, where $55 \%$ of the global market of new connected to the grid capacity in 2012 with 17.2 GW is installed. PV systems consist of a competitive alternative for the decarbonization of Europe's energy sector, as they cover $2.6 \%$ of the electricity demand and $5.2 \%$ of the peak electricity demand. In 2012, $912 \mathrm{MW}$ of PV was installed in Greece, increasing the PV contribution to $4 \%$ of the electricity demands.

Market trends show an expected decrease in the PV system prices from up to $2.31 € / \mathrm{W}$ in 2012 in the residential segment to as low as $1.30 € / \mathrm{W}$ in 2022 [2]. PV market in several countries as Greece is influenced by the political decisions and financial support. Nowadays because of the hard recession there is a decrease in large-scale PV projects installation. However, there is still potential of the Greek PV market to grow.

There is strong correlation between irradiation and temperature [3]. The downward irradiation that reaches the troposphere and the earth surface is absorbed by the atmospheric particles and the earth surface, respectively, emitting back long wave radiation (in the infrared spectrum) that increases the ambient heat and thus the temperature. However, the downward irradiation is largely affected by the cloud cover. Clouds affect the irradiation in three main ways. Firstly, they block a fraction of the direct downward irradiation (and thus affect negatively the direct radiation that reaches the earth surface) [4]. Secondly, they diffuse the already absorbed fraction of the irradiation to all directions, increasing the diffusive irradiation that reaches the earth surface. Thirdly, they block part of the long wave radiation that was supposed to be emitted from earth, back to space (greenhouse effect). The latter affects positively 


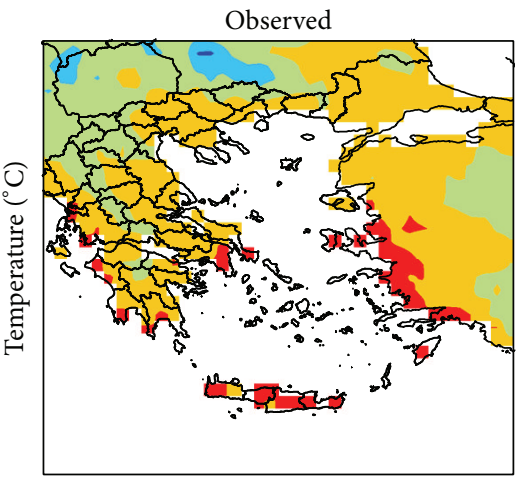

$\left({ }^{\circ} \mathrm{C}\right)$
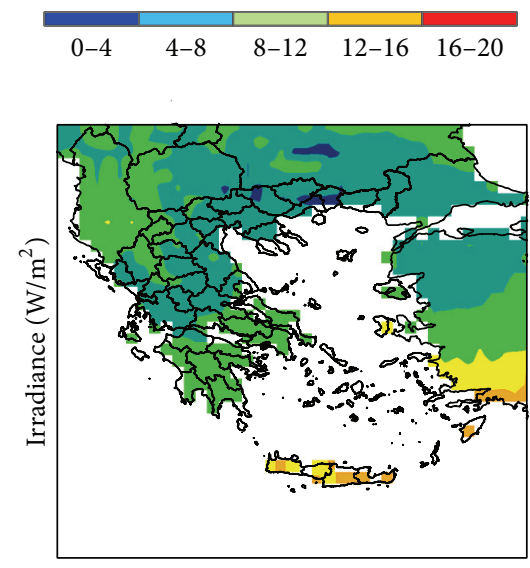

$\left(\mathrm{W} / \mathrm{m}^{2}\right)$

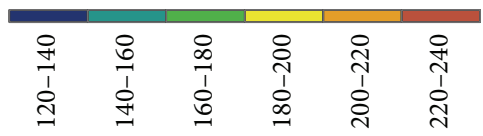

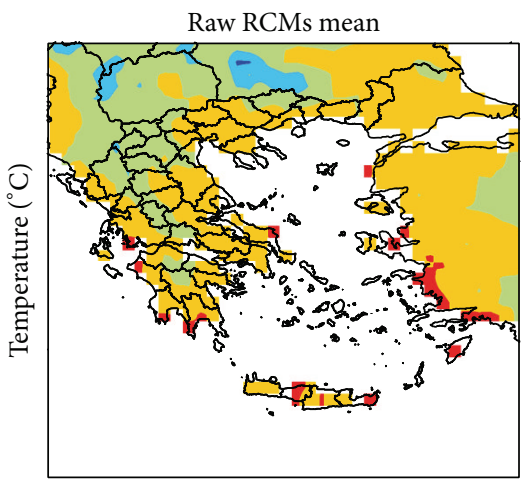

$\left({ }^{\circ} \mathrm{C}\right)$
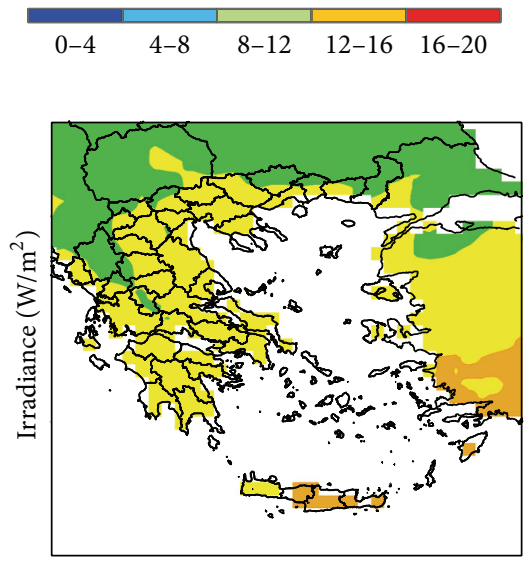

$\left(\mathrm{W} / \mathrm{m}^{2}\right)$

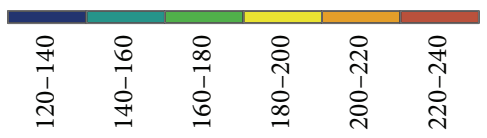

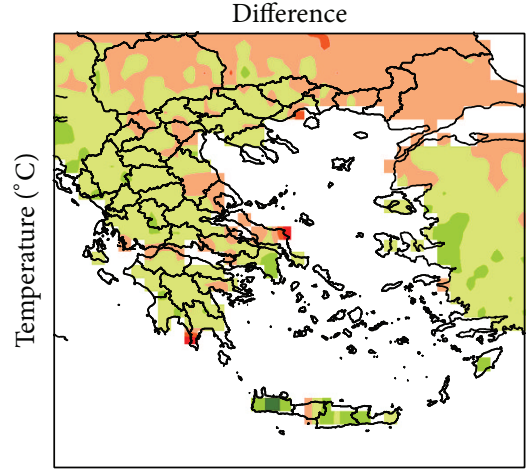

$\left({ }^{\circ} \mathrm{C}\right)$
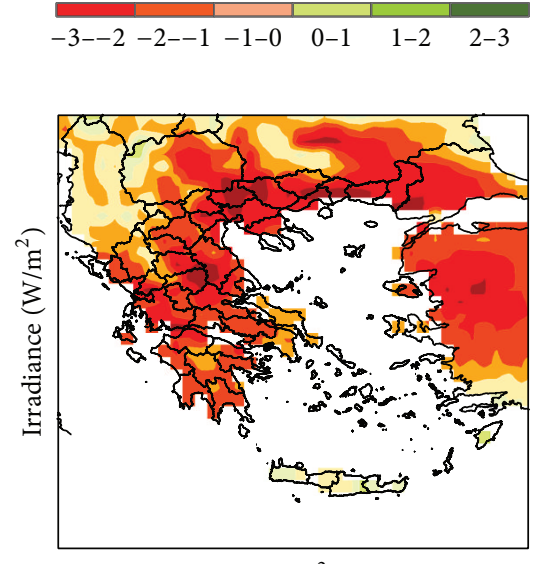

$\left(\mathrm{W} / \mathrm{m}^{2}\right)$

\begin{tabular}{|c|c|c|c|c|c|c|c|c|}
\hline $\begin{array}{l}\text { ㅇ } \\
1 \\
1 \\
0 \\
1\end{array}$ & $\begin{array}{l}0 \\
1 \\
1 \\
1 \\
+1\end{array}$ & $\begin{array}{l}\stackrel{i}{1} \\
1 \\
1 \\
0\end{array}$ & $\begin{array}{l}\stackrel{0}{1} \\
1 \\
1 \\
\stackrel{1}{1}\end{array}$ & & $\vec{\top}$ & & b & 9 \\
\hline
\end{tabular}

FIGURE 1: Maps of average temperature (upper) and irradiance (lower) for the control period based on observations (left panels), the ensemble mean (middle panels), and their difference (right panels).

the near surface air temperature. However, the near surface air temperature is largely affected by the air mass temperature. To account for all these interactions simultaneously, regional climate models (RCMs) are used to produce estimations of surface radiation components and temperature [5].

The performance of PV systems is largely influenced by internal and external factors such as the structural features, visual loss, aging, radiation, shading, temperature, wind, pollution, and electrical losses [6-9]. Climate change will impact temperature and irradiance and therefore will alter the output capacity of PV systems [10]. PV systems present a negative linear relationship between the energy output and the temperature change [11], while the increase of solar radiation is proportional to the PV energy output.

The use of high spatial resolution RCMs has become more common over global circulation models (GCMs), which may not be precise enough to describe local climatic processes [12]. The main disadvantage of RCMs is that model projections have considerable uncertainties. The major sources of uncertainty in climate change research lie in the techniques used to force RCMs with boundary conditions, downscaling methods, and greenhouse gases emissions scenarios [13].

RCMs tend to simulate meteorological data with different statistical characteristics related to the observed-measured values. The time independent component of the error is the bias [14]. Studies [12] have shown that both GCMs and RCMs tend to overestimate the temperature in regions that present wet winters and dry summers and especially during the summer in south-eastern Europe [15]. The use of bias correction is thus required in order to adjust the climate models output according to the existing climate regime. Boberg and Christensen [12], Haerter et al. [14], Christensen et al. [15], and Terink et al. [16] emphasize the necessity of bias correction in order for the forced impact models to derive useful results in hydrology, water resources management, and other climate applications.

The correction methodology depends on the data type, the temporal and spatial resolution of data, and the time scale. In order to cope with the uncertainties related to the different possible detailed realizations of the climate system, 


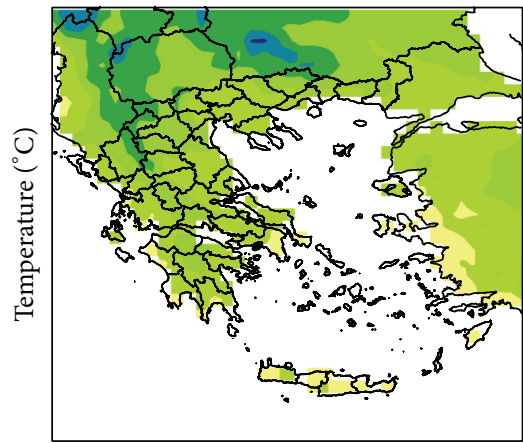

$\left({ }^{\circ} \mathrm{C}\right)$

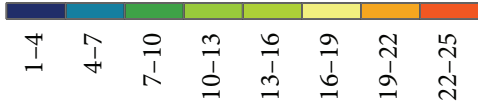

(a)

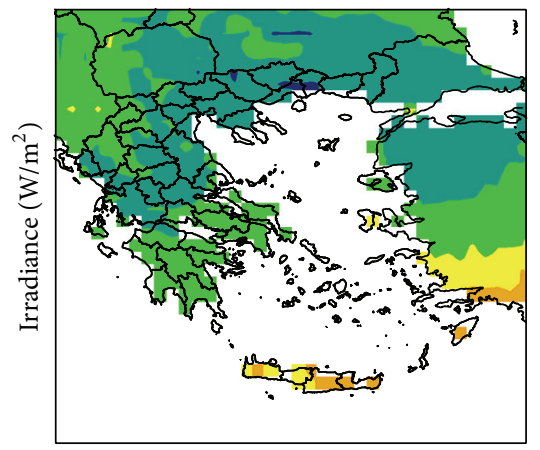

$\left(\mathrm{W} / \mathrm{m}^{2}\right)$

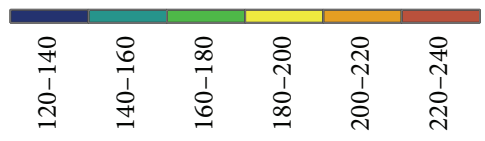

(d)

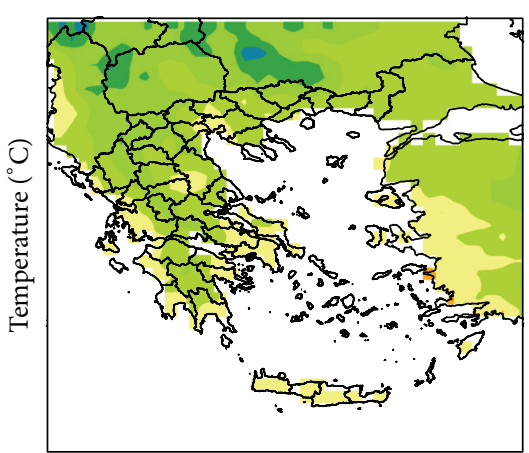

$\left({ }^{\circ} \mathrm{C}\right)$

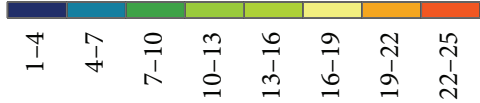

(b)

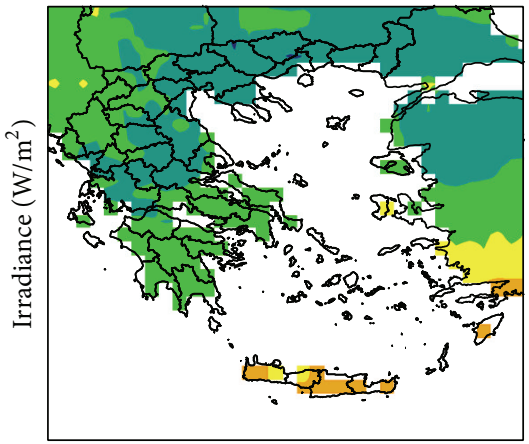

$\left(\mathrm{W} / \mathrm{m}^{2}\right)$

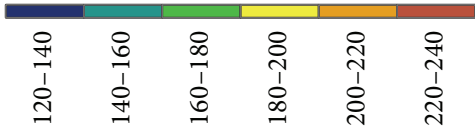

(e)

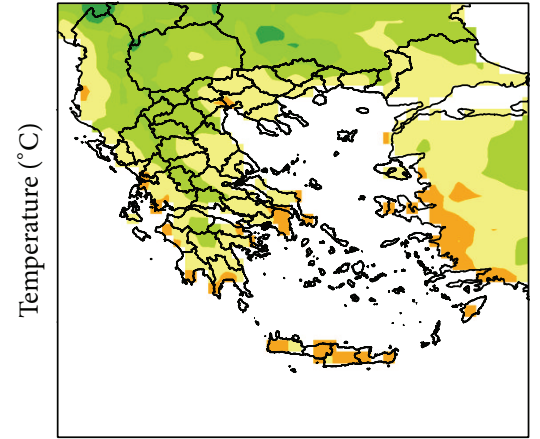

$\left({ }^{\circ} \mathrm{C}\right)$

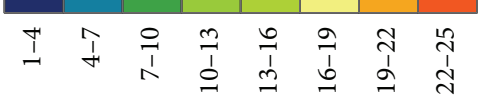

(c)

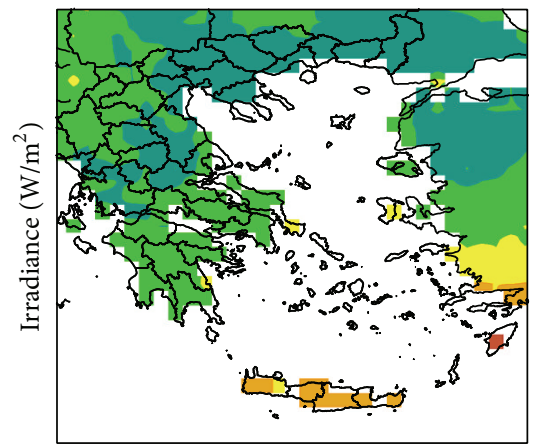

$\left(\mathrm{W} / \mathrm{m}^{2}\right)$

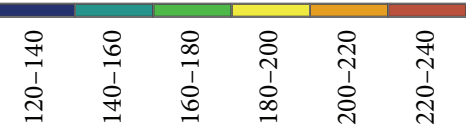

(f)

Figure 2: Mean temperature (upper) and irradiance (lower) fields over Greece for the reference (a, d) period, 2011-2050 period (b, e), and 2061-2100 period (c, f).

ensembles of climate models output are used. Different GCMs can be used to quantify the uncertainty related to the different physical parameterizations of the large-scale land and atmosphere processes. Moreover, different RCMs can also be used to account for the uncertainties related to the representation of smaller scale processes, such as cloud microphysics or precipitation convection.

\section{Methodology}

2.1. Bias Correction. RCM temperature and irradiance outputs were corrected for their biases in mean and standard deviation for each calendar month, following the methodology presented in Haerter et al. [14]. The bias in mean is corrected by subtracting the differences found between observed and modeled values and a correction to the model data is performed to conform to the variability of the historical data. This procedure takes the sequence of anomalies and scales them consistently with the observed historical variability. In the case where data follow normal distribution the transfer function is linear and is of the form shown in the following equation:

$$
\chi_{\mathrm{sc}}^{\mathrm{cor}}=\left(\chi_{\mathrm{mod}}^{\mathrm{sc}}-\overline{\chi_{\mathrm{mod}}^{\mathrm{con}}}\right) *\left(\frac{\sigma_{\mathrm{obs}}^{\mathrm{con}}}{\sigma_{\mathrm{mod}}^{\mathrm{con}}}\right)+\overline{\chi_{\mathrm{obs}}^{\mathrm{con}}}
$$

where $\chi_{\text {sc }}^{\text {cor }}$ is the final adjusted time series, $\chi_{\text {mod }}^{s c}$ is the raw model predictions for the scenario period, $\chi_{\mathrm{obs}}^{\mathrm{con}}$ and $\chi_{\bmod }^{\mathrm{con}}$ are the mean of observed and modeled data for the control period, respectively, and $\sigma_{\text {obs }}^{\text {con }}$ and $\sigma_{\text {mod }}^{\text {con }}$ are the standard deviations of observed and modeled data for the control period, respectively.

The final adjusted model time series exhibits the appropriate baseline mean and standard deviation with respect to the observed data.

2.2. Estimation of PV Energy Output under Variable Conditions of Temperature and Irradiance. In order to estimate 


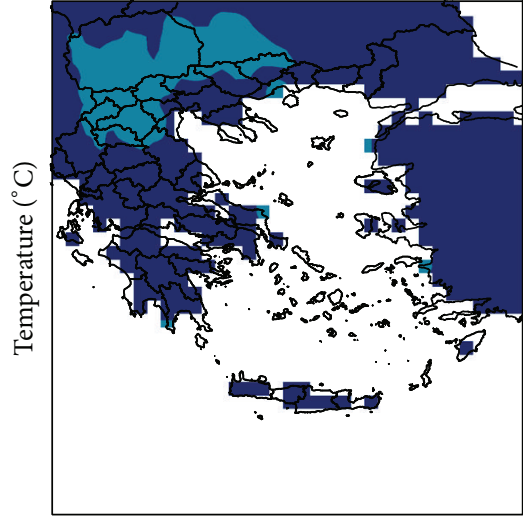

$\left({ }^{\circ} \mathrm{C}\right)$

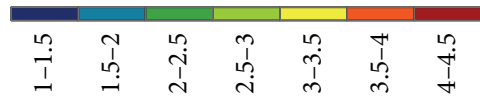

(a)

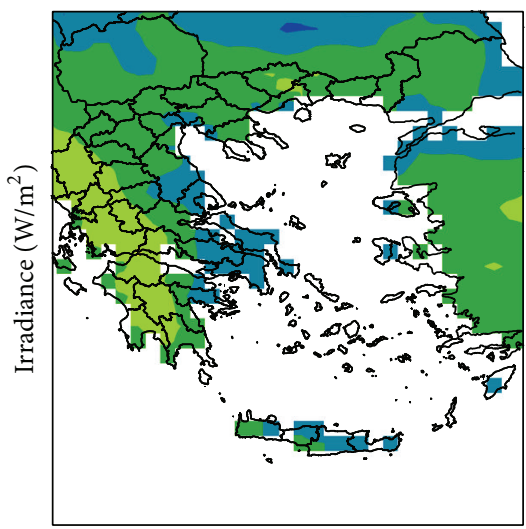

$\left(\mathrm{W} / \mathrm{m}^{2}\right)$

$\begin{array}{lllllll}-1-0 & 1-2 & 0-1 & 2-3 & 3-4 & 4-5 & 5-6\end{array}$

(c)

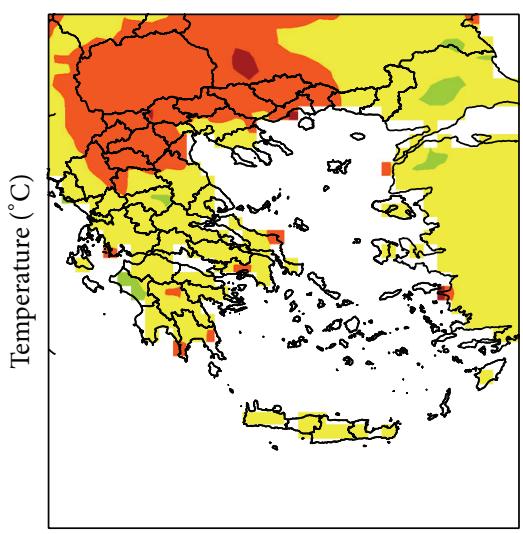

$\left({ }^{\circ} \mathrm{C}\right)$

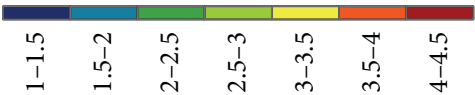

(b)

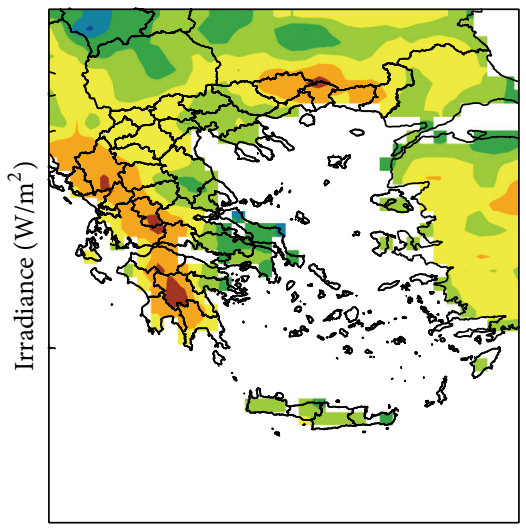

$\left(\mathrm{W} / \mathrm{m}^{2}\right)$

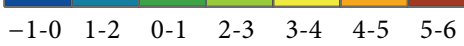

(d)

Figure 3: Absolute difference between reference and 2011-2050 period (a, c) and between reference and 2061-2100 (b, d) for temperature (upper) and irradiance (lower).

the potential percentage change in PV output, the fractional change $\Delta P_{\mathrm{PV}} / P_{\mathrm{PV}}$ is calculated from the ratio between (2) and (3) taken from Crook et al. [10]. Consider the following:

$$
\begin{aligned}
& \frac{\Delta \mathrm{P}_{\mathrm{PV}}}{\eta_{\mathrm{ref}}} \\
& =-\Delta \mathrm{T} G_{\text {tot }} \beta c_{2}+\Delta G_{\text {tot }}\left(1-\beta c_{1}+\beta T_{\text {ref }}-2 \beta c_{3}-T \beta c_{2}\right) \\
& \quad-\Delta G_{\text {tot }}^{2} \beta c_{3}-\Delta G_{\text {tot }} \Delta \mathrm{T} \beta c_{2}+\Delta G_{\text {tot }} \gamma \log _{10}\left(G_{\text {tot }}+\Delta G_{\text {tot }}\right) \\
& \quad+G_{\text {tot }} \gamma \log _{10}\left(\frac{G_{\text {tot }}+\Delta G_{\text {tot }}}{G_{\text {tot }}}\right),
\end{aligned}
$$

$$
\frac{P_{\mathrm{PV}}}{\eta_{\mathrm{ref}}}=G_{\mathrm{tot}}\left(1-\beta\left(c_{1}+c_{2} T+c_{3} G_{\mathrm{tot}}-T_{\mathrm{ref}}\right)+\gamma \log _{10} G_{\mathrm{tot}}\right)
$$

where $\Delta P_{\mathrm{PV}}$ is the change in photovoltaic power output, $\eta_{\mathrm{ref}}$ is the reference photovoltaic efficiency, $\Delta T$ is the change in temperature between the baseline and the scenario period, $\Delta G$ is the change in irradiance between the baseline and the scenario period, $T$ is the daytime temperature for the baseline period, estimated by (4) as it can be found in Crook et al. [10], $G_{\text {tot }}$ is the irradiance over the daylight for the actual cloud cover for the baseline period, calculated by (5) taken from Crook et al. [10], and $T_{\text {ref }}$ is the reference temperature in which the performance of PV cell is estimated by the manufacturer. $\beta$ is the temperature coefficient set by cell 


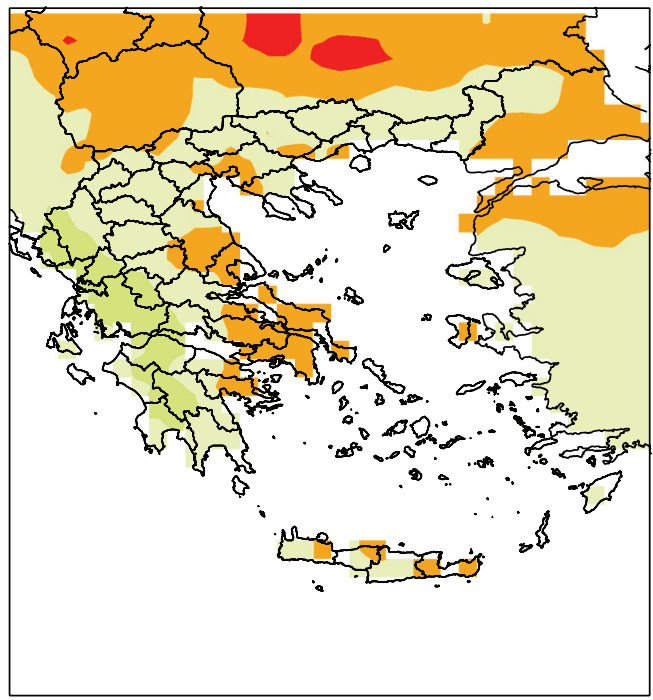

(\%)

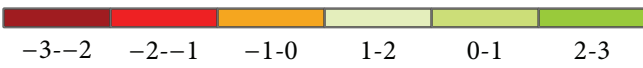

(a)

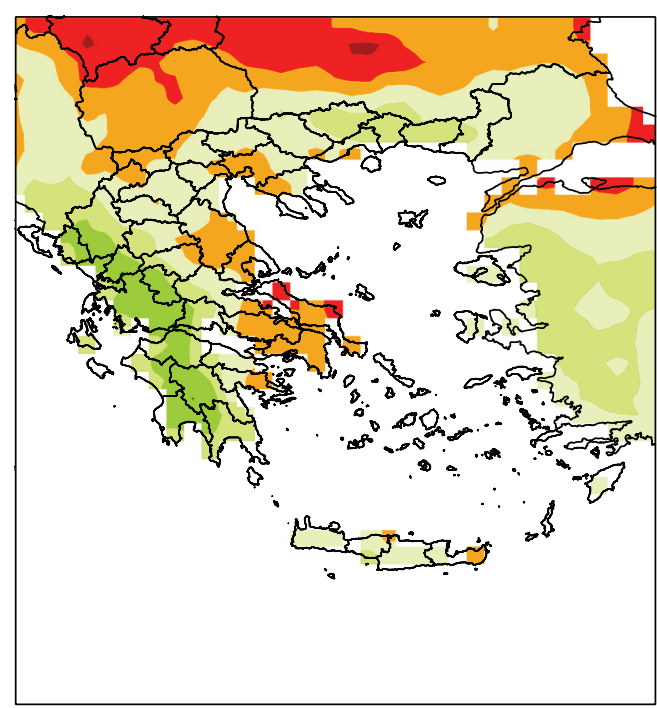

$(\%)$

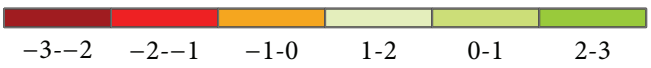

(b)

FIGURE 4: Estimated change in PV output for (a) the 2011-2050 period and (b) for the 2061-2100 period.

material and structure, $\gamma$ is the irradiance coefficient set by cell material and structure, and $c_{1}, c_{2}$, and $c_{3}$ are coefficients which depend on details of the module and mounting that affect heat transfer from the cell. Consider the following:

$$
T=\bar{T}+\frac{\overline{\mathrm{DTR}}}{4},
$$

where DTR is the diurnal range of the temperature (difference between minimum and maximum temperature) and $\bar{T}$ is the monthly average temperature. Consider

$$
G_{\text {tot }}=\bar{G} \frac{t_{24 \mathrm{~h}}}{t_{\text {daylength }}},
$$

where $\bar{G}$ is the monthly average irradiance and $t_{\text {daylength }}$ is the time of the daylight, calculated as monthly average, for all latitudes of the study site every $0.25^{\circ}$.

\section{Case Study Area and Data Used}

Monthly means of surface temperature and irradiance projections were obtained for five regional climate models of the ENSEMBLES (http://ensemblesrt3.dmi.dk/) database, under the special report on emissions scenarios (SRES) A1B emission scenario of the Intergovernmental Panel on Climate Change (IPCC). The main objectives of the ENSEMBLES project were to provide an ensemble prediction system based on the state of the art of high resolution global and regional earth system models developed in Europe. The produced simulations were validated by using high resolution gridded datasets for Europe to produce an objective probabilistic estimate of uncertainty in future climate at the seasonal to decadal and longer timescales. More information about the ENSEMBLES project can be found in UK Met Office page http://ensembles-eu.metoffice.com/ [21]. Detailed information about used RCMs temporal resolution is presented in Table 1. The processing of the climate data was performed in the ENSEMBLES RCMs spatial resolution which is 0.25 degrees.

The E-OBS [22] dataset provided observed minimum and maximum temperature data between 1950 and 2000 . The SoDa database (http://www.soda-is.com) between 1985 and 2005 with spatial resolution of $20 \mathrm{~km}$ was used as an observational irradiance dataset. The SoDa server provides daily irradiation time series over Europe, Africa, and Atlantic Ocean, which is accessible on a free basis [23]. It supplies information of high quality, matching the actual needs of users, with improved time-space coverage and sampling [24]. The SoDa irradiance is satellite derived data of HelioClim-1 Daily Solar Irradiance v4.0 (HelioClim-1 Database of Daily Solar Irradiance v4.0 derived from satellite data, MINES ParisTech, Armines, France). HelioClim databases use the Heliosat-2 [25] method to process the Meteosat Images. The Heliosat method converts images acquired by meteorological geostationary satellites, such as Meteosat (Europe), GOES (USA) or GMS (Japan), into data and maps of solar radiation received at ground level. Mines ParisTech produced the method Heliosat-2 in November 2002, partly with the support of the European Commission (project SoDa Contract DG "INFSO" IST-1999-12245). The accuracy of the HelioClim-1 data is discussed in detail by Lefèvre et al. [26]. They assessed the accuracy of the HelioClim-1 data against ground measurements of the WMO radiometric network (55 

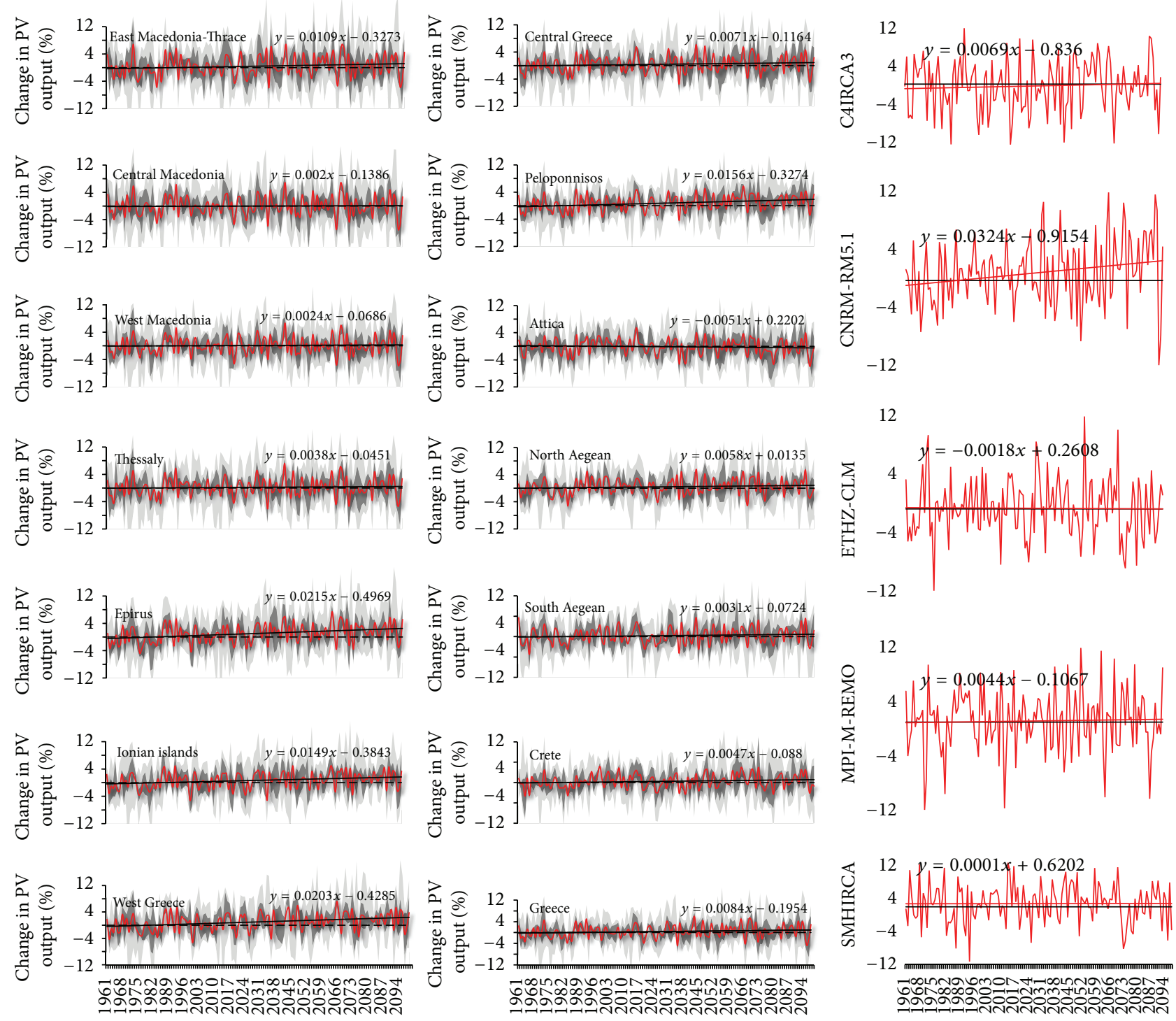

FIGURE 5: Relative change in PV output for the 13 prefectures of Greece and for the entire Greek region (left and center). Red line shows the average change of all models, dark grey represents the 50\% range of the values of all RCMs, and light grey shows the $100 \%$ range of the models. Subplots in the right are the ensemble mean of each RCM for entire Greek region. The relative change is estimated using the 1960-2000 as baseline period.

TABLE 1: Name, institute, driving GCM, and transient experiment period of each ENSEMBLES RCM used.

\begin{tabular}{lccr}
\hline Acronym & Institute & Driving GCM & Duration \\
\hline C4IRCA3 [17] & SMHI, Sweden & HadCM3Q16 & $1951-2100$ \\
ETHZ-CLM [18] & ETHZ, Switzerland & HadCM3Q0 & $1951-2099$ \\
MPI-M-REMO [19] & MPI, Germany & ECHAM5-r3 & $1951-2100$ \\
SMHIRCA [17] & SMHI, Sweden & BCM & $1961-2099$ \\
CNRM-RM5.1 [20] & CNRM, France & APREGE_RM5.1 & $1950-2100$ \\
\hline
\end{tabular}

sites in Europe and 35 in Africa) between 1994 and 1997. The RMS error was found to be $35 \mathrm{~W} / \mathrm{m}^{2}$ (17\%) for daily mean irradiance and $25 \mathrm{~W} / \mathrm{m}^{2}$ (12\%) for monthly mean irradiance. However, the bias of HelioClim against the observations was found to be in overall less than $1 \mathrm{~W} / \mathrm{m}^{2}$ for the whole dataset.
The estimation of the change in $P / V$ potential over Greece was conducted at NUTS2 spatial discretization level (NUTS: nomenclature of units for territorial statistics). Moreover, standard coefficients of monocrystalline silicon cells were considered for (2) and (3). For a monocrystalline silicon cell 


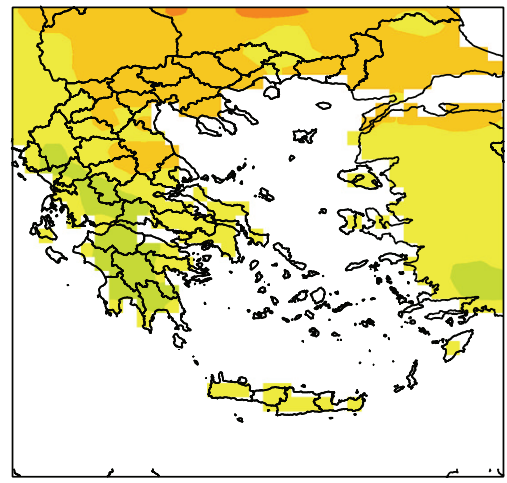

(\%)

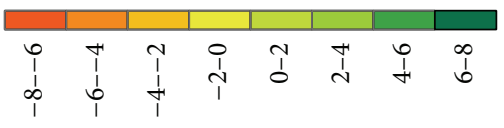

(a)

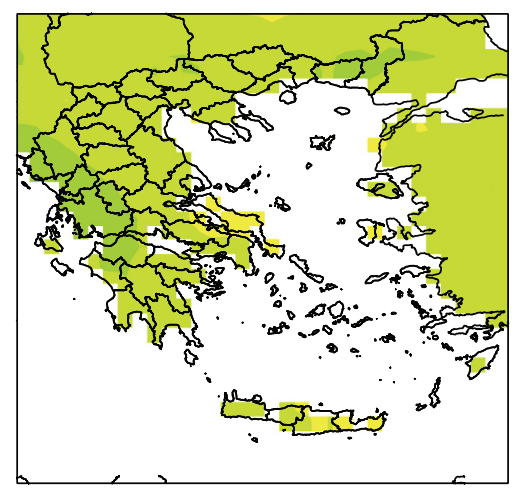

(\%)

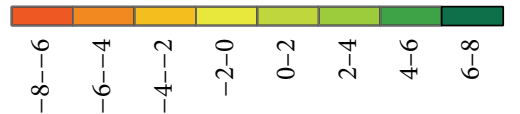

(b)

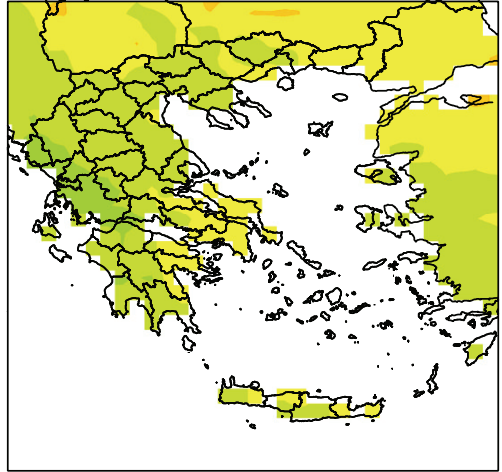

$(\%)$

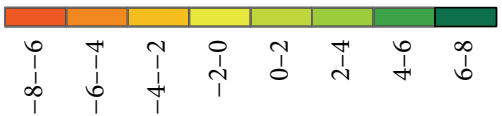

(c)

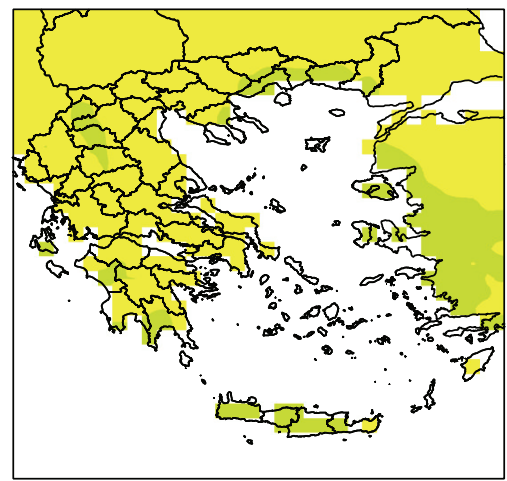

(\%)

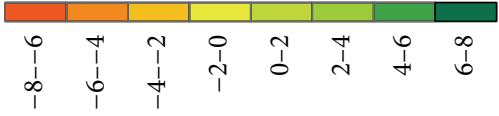

(d)

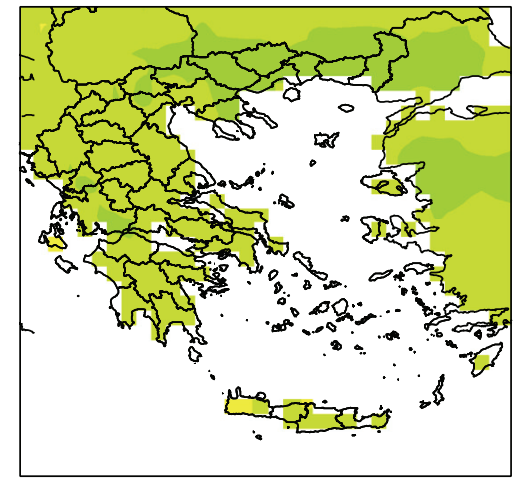

(\%)

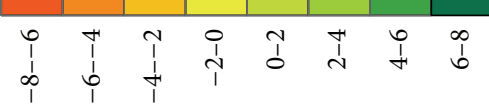

(e)

FIGURE 6: The first projection period (2011-2050) results in PV output change as it was estimated from each RCM ((a): C4I-RCA3, (b): CNRM-RM5.1, (c): ETHZ-CLM, (d): MPI-M-REMO, and (e): SMHI-RCA).

the coefficients are set according to Lasiner and Ang [27] as it is proposed in Crook et al. [10]. Thus, $\beta=0.0045, \gamma=0.1$, $c_{1}=-3.75^{\circ} \mathrm{C}, c_{2}=1.14$, and $c_{3}=0.0175^{\circ} \mathrm{Cm}^{2} \mathrm{~W}^{-1}$. Typical value for the reference temperature is $T_{\text {ref }}=25^{\circ} \mathrm{C}$.

\section{Results}

4.1. Change in PV Energy Output. The change in PV energy output was estimated for two subsequent projection periods, 2011-2050 and 2061-2100. The periods 1950-2000 for temperature and 1985-2005 for irradiance were defined as control periods. Figure 1 presents the observed, the raw model ensemble mean, and the difference between them for temperature and irradiation. It was found that the RCM ensemble mean overestimates the mean temperature over Greek domain from $1^{\circ} \mathrm{C}$ to $3^{\circ} \mathrm{C}$. This was also mentioned in Boberg and Christensen [12]. Similarly, RCM data tend to heavily overestimate the irradiance over central parts of Greece with the overestimation to be as high as from $40 \mathrm{~W} / \mathrm{m}^{2}$ to $50 \mathrm{~W} / \mathrm{m}^{2}$ in some parts. However, over the southernmost part of Greece, RCMs represent better the mean irradiation. The difference between the observed and model values stresses the need of adjusting the bias in both the examined parameters. Figure 2 shows the change in RCM simulated mean irradiance and temperature for the three considered 40-year periods, after the adjustment of the bias. The relative change in mean for the two projected periods is also presented in Figure 3 compared to the control period. It is shown that in the first projection period (2011-2050) the mean increase ranges between 1 and $1.5^{\circ} \mathrm{C}$, while by $2061-2100$ period the increase range reaches up to $3-3.5^{\circ} \mathrm{C}$ for the most parts of the study area. Regarding irradiance the average increase for the first projection period ranges between 2 


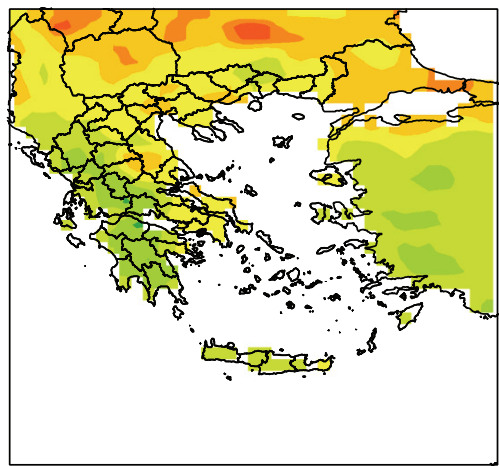

(\%)

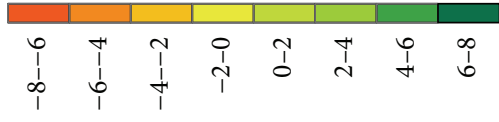

(a)

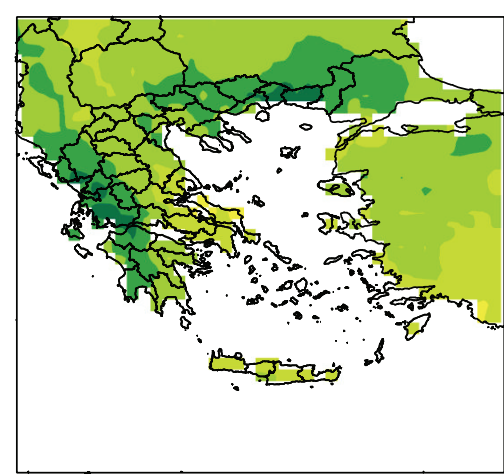

(\%)

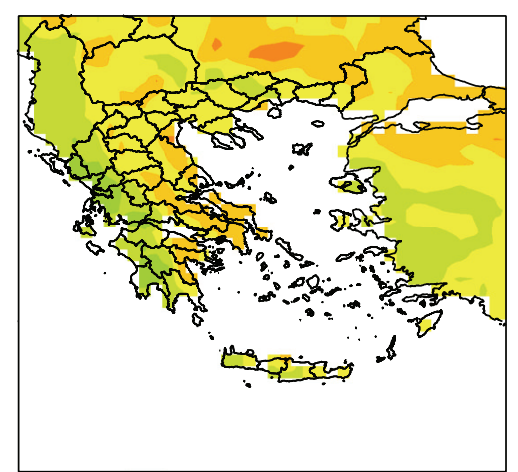

(\%)

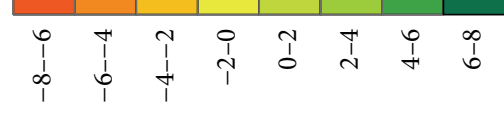

(b)

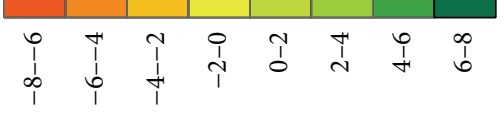

(c)

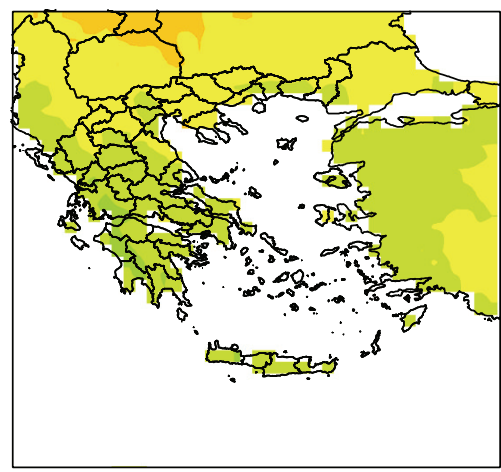

(\%)

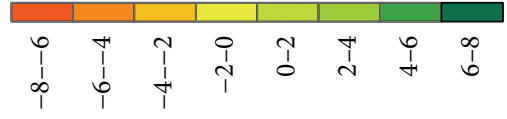

(d)

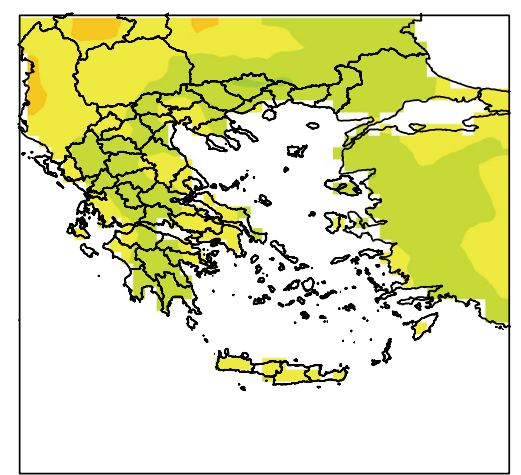

(\%)

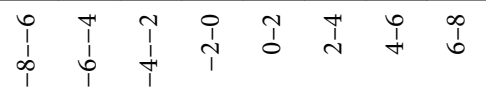

(e)

FIGURE 7: The second projection period (2061-2100) results in PV output change as it was estimated from each RCM ((a): C4I-RCA3, (b): CNRM-RM5.1, (c): ETHZ-CLM, (d) MPI-M REMO, and (e): SMHI-RCA).

and $3 \mathrm{~W} / \mathrm{m}^{2}$ while for the second period there is a further increase of $2-5 \mathrm{~W} / \mathrm{m}^{2}$. More specifically, the largest increase is expected over central Peloponnese and over Western Greece, in the regions of Epirus and Western Macedonia.

The change in PV energy output was then estimated for each model and projection period. Figure 4 illustratesthe projected mean change in PV output derived from the ensemble of the RCMs. By 2050 the average PV energy output could increase up to $1 \%-2 \%$ in Western and Southwestern Greece, whereas for the regions of Attica and Thessaly a decrease of $1 \%$ is projected. However in the second period Western Greece and specifically the regions of Epirus and Peloponnese are projected to have an increase from $2 \%$ to $3 \%$. For Thrace the respective increase is projected to be near $2 \%$; in Northern Greece (Macedonia), Crete, and Aegean islands, the PV performance is expected to increases up to $1 \%$ while in the regions of Attica and Thessaly the projected performance decreases up from $1 \%$ to $2 \%$.
Figure 5 illustrates the long term trend of the models ensemble relative projected change in PV energy output, for all administrative regions of Greece (NUTS 2 level) and for the entire study area. For all administrative regions, except Attica, a slight increasing trend in PV output is expected during the 21 st century ranging between $0.2 \%$ and $2 \%$ in the regions of Western Greece and Epirus.

It is important to note that in Figure 5, the range of relative change from all models values is between $\pm 12 \%$, which indicates the models' uncertainty. Referring to Crook et al. [10], the uncertainty in the specific research lies in the uncertainty of the projected changes in temperature and insolation. The most important source of uncertainty is the changes of cloud cover [28] and behavior as simulated in climate models, which plays an important role in climate change projections for the 21st century. For Southern Europe a decrease in cloud cover and increase in surface radiation are projected [10]. Therefore without the change in cloud cover 


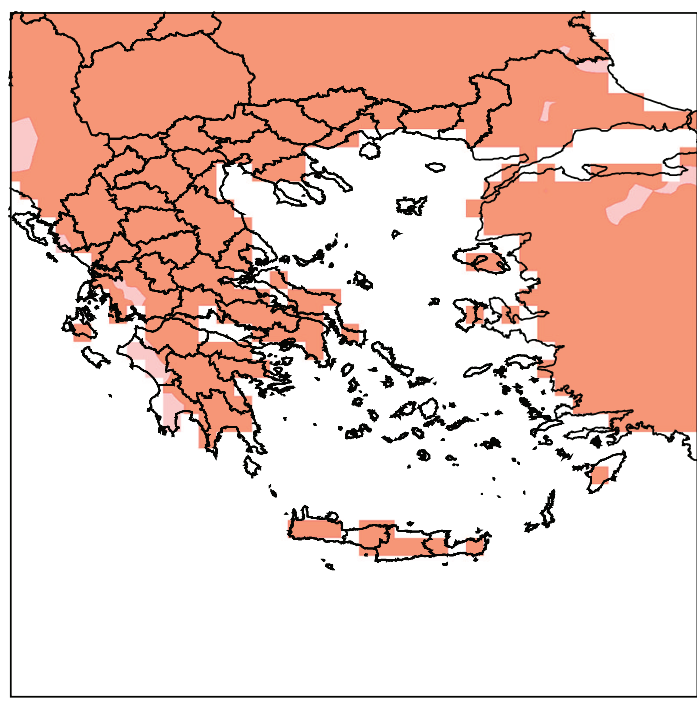

$(\%)$

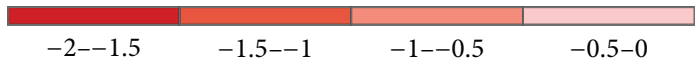

(a)

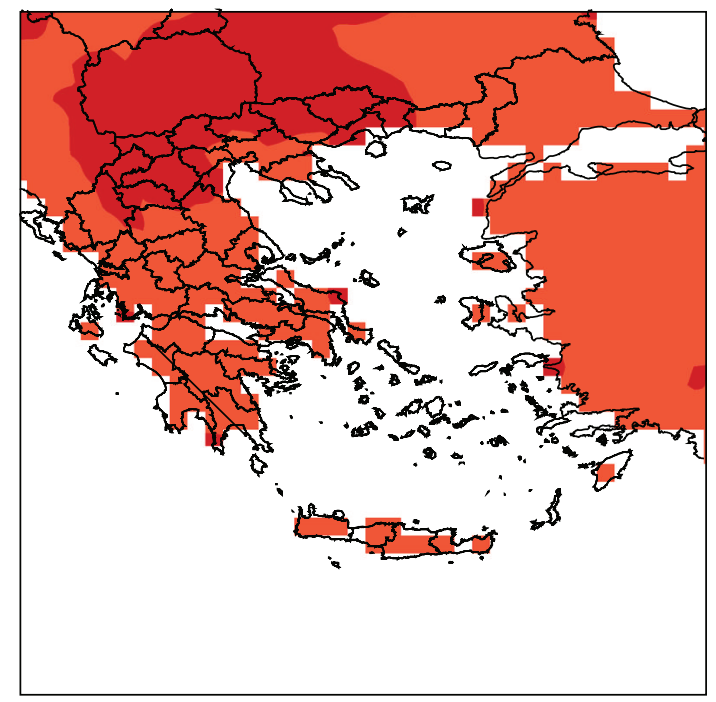

(\%)

\begin{tabular}{lll|l}
\hline$-2--1.5$ & $-1.5--1$ & $-1--0.5$ & $-0.5-0$
\end{tabular}

(b)

FIGURE 8: Temperature contribution to \% PV output for 2011-2050 (a) and 2061-2100 (b) periods.

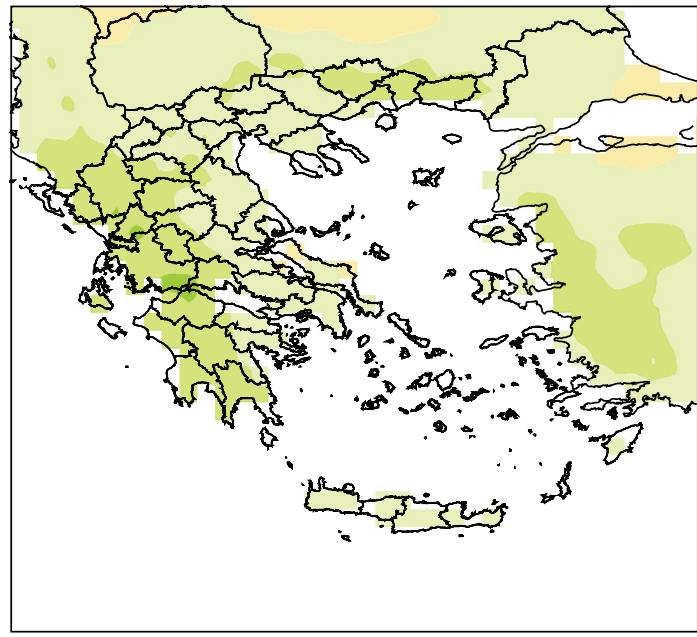

(\%)

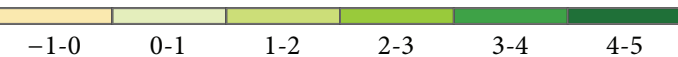

(a)

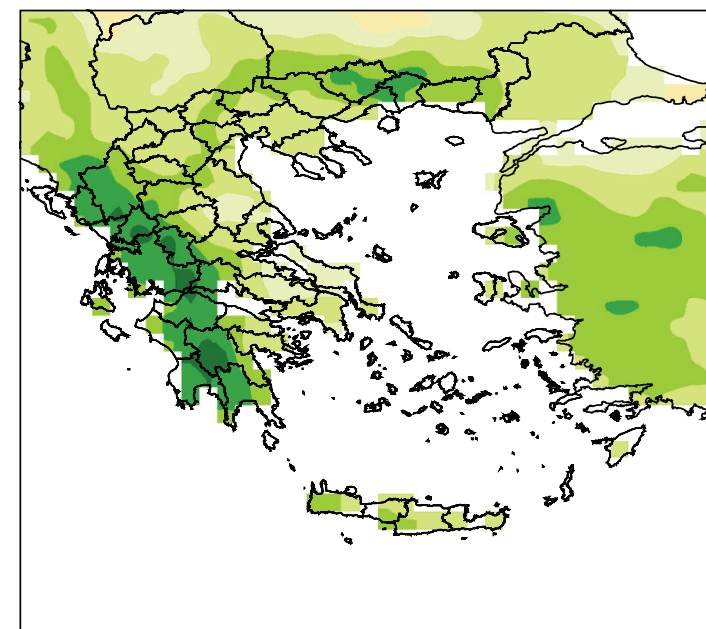

(\%)

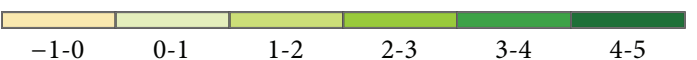

(b)

FIGURE 9: Irradiance contribution to \% PV output for 2011-2050 (a) and 2061-2100 (b) periods.

the warming would still exist but not at this extend. Changes in cloud coverage influence the diurnal temperature variation [22] with greater influence on $T_{\max }$ during summer and $T_{\min }$ during winter than on the average daily temperature. This necessitates the distinctive consideration of $T_{\max }$ and $T_{\min }$ in climate change impact research. For Europe an increase in DTR (diurnal temperature range-temperature difference between maximum and minimum daily temperatures) is projected with greater uncertainty in the local summer season variation [29].

Figures 6 and 7 present the percentage change of PV performance as derived from each RCM for 2011-2050 and 2061-2100 periods, respectively, compared to the RCMs outputs for the reference period. Results indicate that the signal of the projected change in average PV performance over Greece is robust with large spatial variability, however, 
among the different RCMs. The majority of the RCMs project an increase between $1 \%$ and $2 \%$ over the most regions of the study area for the first period of study except from the RCM C4IRCA3 model which predicts a decrease up to $4 \%$ over the regions of Central and East Macedonia and the RCM MPIM-REMO model which shows a decrease of about $2 \%$. The projection for the second period indicates that, except for the RCM CNRM-RM 5.1 which shows a large increase, the rest of the RCM models predict an increase of the productivity of PV systems in the western mainland, Peloponnese, and Crete about $2 \%$, while in the eastern mainland a decrease in productivity of about $2 \%$ and above is shown.

4.2. Contribution of Temperature and Insolation in the $P V$ Output Change. The relative contributions of $\Delta T$ and $\Delta G$ are estimated by setting the projected change in irradiance and temperature, respectively, equal to zero in the calculations for the potential percentage change in the PV energy output in (2) following the methodology presented in Crook et al. [10]. In Figure 8, the ensemble mean PV output change is estimated for both projected periods, by setting the irradiance change equal to zero. In Figure 9 the respective results are presented by setting the temperature change equal to zero. The individual change in irradiance results in a significant increase on PV energy output up to $5 \%$ while the increase of temperature causes a decrease up to $2 \%$. The relative contribution of each parameter varies from region to region. As it is expected, the two factors present different correlation signals with the PV output. In some cases the change in temperature and irradiance mutually compensates resulting in a small net change in performance. This is mostly the case in the first study period. However, there are cases such as the eastern part of Greece (Attica, Thessaly) where an increase in temperature of about $3^{\circ} \mathrm{C}-3.5^{\circ} \mathrm{C}$ cannot be compensated by the irradiation increase of about $1-3 \mathrm{~W} / \mathrm{m}^{2}$ and the estimation of PV energy output is negative, resulting in an overall reduction of $\mathrm{PV}$ output up to $3 \%$. In contrast, over the Western Greece, despite the temperature increase at the same levels, the overall performance is expected to increase due to significant irradiation increase as a result of lower cloud coverage. Nonetheless, in some cases the large temperature increase cannot be compensated by the increase irradiance, as it can be observed in both study periods in eastern parts of the Greek mainland, some areas in Central Macedonia, and over Crete.

\section{Conclusions}

The projections of temperature and irradiance from 5 RCMs were analyzed for their contribution to monoclystalic PV panels' output change, over Greece. The analysis was conducted for two future periods, 2011-2050 and 2061-2100. The RCMs project an average temperature increase up to $1.5^{\circ} \mathrm{C}$ for the period $2011-2050$ and from $3^{\circ} \mathrm{C}$ to $3.5^{\circ} \mathrm{C}$ for the period 2061-2100. Regarding the irradiance projections, an increase of $2-3 \mathrm{~W} / \mathrm{m}^{2}$ by $2011-2050$ and up to $5 \mathrm{~W} / \mathrm{m}^{2}$ by $2061-2100$ could be expected.
The PV output is projected to have an increasing trend for all regions of Greece during the 21st century. The region of Attica is an exemption where a reduction of $0.5 \%$ is projected. In the first period of study, an average increase between 1 and $2 \%$ in the majority of the study area is likely to occur except for the region of Attica and some areas in Thessaly and Central Macedonia. During the second period (2061-2100) a significant increase in the PV output is projected over the western mainland of Greece and Peloponnese, while a mild decrease for the eastern mainland and Central Macedonia is expected.

Examining the relative contributions of temperature and irradiance, a significant reduction due to the temperature increase is foreseen which is, however, outweighed by the irradiance increase, resulting in an overall increase in photovoltaic systems.

While the analysis shows clear increasing trends in the output of the monocrystalline PV systems over Greece, the rate of increase is small comparing to the variability amongst different RCMs. This is mainly attributed to the RCM shortcoming to robustly project the cloud cover and thus the irradiation parameter. The model's ability to capture the irradiation is expected to improve in the forthcoming Euro CORDEX [30].

\section{Conflict of Interests}

The authors declare that there is no conflict of interests regarding the publication of this paper.

\section{Acknowledgments}

The authors acknowledge the E-OBS dataset from the EU-FP6 project ENSEMBLES (http://ensembles-eu.metoffice .com) and the data providers in the ECA\&D project (http:// www.ecad.eu). The ENSEMBLES (http://ensemblesrt3.dmi $. \mathrm{dk} /$ ) database provided the RCM data used in this study. The SoDa database (SoDa Contract DG “INFSO" IST-199912245) provided the observed irradiance data used. This research work was funded by the EU FP7 ECLISE project (Grant Agreement no. 265240).

\section{References}

[1] EPIA, Global Market Outlook for Photovoltaics 2013-2017, European Photovoltaic Industry Association, 2013.

[2] EPIA, Connecting the Sun-Solar Photovoltaics on the Road to Large-Scale Grid Integration, European Photovoltaic Industry Association, 2012.

[3] M. Wild, A. Ohmura, and K. Makowski, "Impact of global dimming and brightening on global warming," Geophysical Research Letters, vol. 34, no. 4, Article ID L04702, 2007.

[4] D. Aiguo, K. E. Trenberth, and T. R. Karl, "Effects of clouds, soil moisture, precipitation, and water vapor on diurnal temperature range," Journal of Climate, vol. 12, no. 8, pp. 2451-2473, 1999.

[5] R. F. Cahalan, G. Wen, J. W. Harder, and P. Pilewskie, “Temperature responses to spectral solar variability on decadal time scales," Geophysical Research Letters, vol. 37, no. 7, 2010. 
[6] M. Mani and R. Pillai, "Impact of dust on solar photovoltaic (PV) performance: research status, challenges and recommendations," Renewable and Sustainable Energy Reviews, vol. 14, no. 9, pp. 3124-3131, 2010.

[7] M. E. Meral and F. Diner, "A review of the factors affecting operation and efficiency of photovoltaic based electricity generation systems," Renewable and Sustainable Energy Reviews, vol. 15, no. 5, pp. 2176-2184, 2011.

[8] F. Dincer and M. E. Meral, "Critical factors that affecting efficiency of solar cells," Smart Grid and Renewable Energy, vol. 1, pp. 47-50, 2010.

[9] E. Skoplaki and J. A. Palyvos, "On the temperature dependence of photovoltaic module electrical performance: A review of efficiency/power correlations," Solar Energy, vol. 83, no. 5, pp. 614-624, 2009.

[10] J. A. Crook, L. A. Jones, P. M. Forster, and R. Crook, "Climate change impacts on future photovoltaic and concentrated solar power energy output," Energy and Environmental Science, vol. 4, no. 9, pp. 3101-3109, 2011.

[11] G. Notton, C. Cristofari, M. Mattei, and P. Poggi, "Modelling of a double-glass photovoltaic module using finite differences," Applied Thermal Engineering, vol. 25, no. 17-18, pp. 2854-2877, 2005.

[12] F. Boberg and J. H. Christensen, "Overestimation of Mediterranean summer temperature projections due to model deficiencies," Nature Climate Change, vol. 2, no. 6, pp. 433-436, 2012.

[13] J. Chen, F. P. Brissette, and R. Leconte, "Uncertainty of downscaling method in quantifying the impact of climate change on hydrology," Journal of Hydrology, vol. 401, no. 3-4, pp. 190-202, 2011.

[14] J. O. Haerter, S. Hagemann, C. Moseley, and C. Piani, "Climate model bias correction and the role of timescales," Hydrology and Earth System Sciences, vol. 15, no. 3, pp. 1065-1079, 2011.

[15] J. H. Christensen, F. Boberg, O. B. Christensen, and P. LucasPicher, "On the need for bias correction of regional climate change projections of temperature and precipitation," Geophysical Research Letters, vol. 35, no. 20, Article ID L20709, 2008.

[16] W. Terink, R. T. W. L. Hurkmans, P. J. J. F. Torfs, and R. Uijlenhoet, "Bias correction of temperature and precipitation data for regional climate model application to the Rhine basin," Hydrology and Earth System Sciences Discussions, vol. 6, no. 4, pp. 5377-5413, 2009.

[17] E. Kjellstrom, L. Barring, S. Gollvik et al., "A 140-year simulation of European climate with the new version of the Rossby Centre regional atmospheric climate model (RCA3)," SMHI Reports Meteorology and Climatology, 108, SMHI, SE-60176 Norrkoping, Sweden, 2005.

[18] U. Bohm, M. Kucken, W. Ahrens et al., "CLM-the climate version of LM: brief description and long-term applications," COSMO Newsletter, vol. 6, 2006.

[19] D. Jacob, "A note to the simulation of the annual and interannual variability of the water budget over the Baltic Sea drainage basin," Meteorology and Atmospheric Physics, vol. 77, no. 1-4, pp. 61-73, 2001.

[20] R. Radu, M. Déqué, and S. Somot, "Spectral nudging in a spectral regional climate model," Tellus A: Dynamic Meteorology and Oceanography, vol. 60, no. 5, pp. 898-910, 2008.

[21] C. D. Hewitt and D. J. Griggs, "Ensembles-based predictions of climate changes and their impacts," Eos, vol. 85, no. 52, p. 566, 2004.
[22] M. R. Haylock, N. Hofstra, A. M. G. Klein Tank, E. J. Klok, P. D. Jones, and M. New, "A European daily high-resolution gridded data set of surface temperature and precipitation for 1950-2006," Journal of Geophysical Research D: Atmospheres, vol. 113, no. 20, Article ID D20119, 2008.

[23] S. Cros, D. Mayer, and L. Wald, "The availability of irradiation data," Report IEA-PVPS T2-04, International Energy Agency, Photovoltaic Power System Programme, Centre d' Energetique, Ecole des Mines de Paris/Armines, Antipolis, France, 2004.

[24] B. Gschwind, L. Ménard, M. Albuisson, and L. Wald, "Converting a successful research project into a sustainable service: the case of the SoDa Web service," Environmental Modelling and Software, vol. 21, no. 11, pp. 1555-1561, 2006.

[25] C. Rigollier, M. Lefèvre, and L. Wald, "The method Heliosat2 for deriving shortwave solar radiation from satellite images," Solar Energy, vol. 77, no. 2, pp. 159-169, 2004.

[26] M. Lefèvre, L. Wald, and L. Diabaté, "Using reduced data sets ISCCP-B2 from the Meteosat satellites to assess surface solar irradiance," Solar Energy, vol. 81, no. 2, pp. 240-253, 2007.

[27] F. Lasiner and T. G. Ang, Photovoltaic Engineering Handbook, Adam Higler, Princeton, NJ, USA, 1990.

[28] K. E. Trenberth and J. T. Fasullo, "Global warming due to increasing absorbed solar radiation," Geophysical Research Letters, vol. 36, Article ID L07706, 2009.

[29] D. B. Lobell, C. Bonfils, and P. B. Duffy, "Climate change uncertainty for daily minimum and maximum temperatures: a model inter-comparison," Geophysical Research Letters, vol. 34, no. $5,2007$.

[30] D. Jacob, J. Petersen, B. Eggert et al., EURO-CORDEX: New High-Resolution Climate Change Projections for European Impact Research Regional Environmental Change, Springer, Berlin, Germany, 2013. 

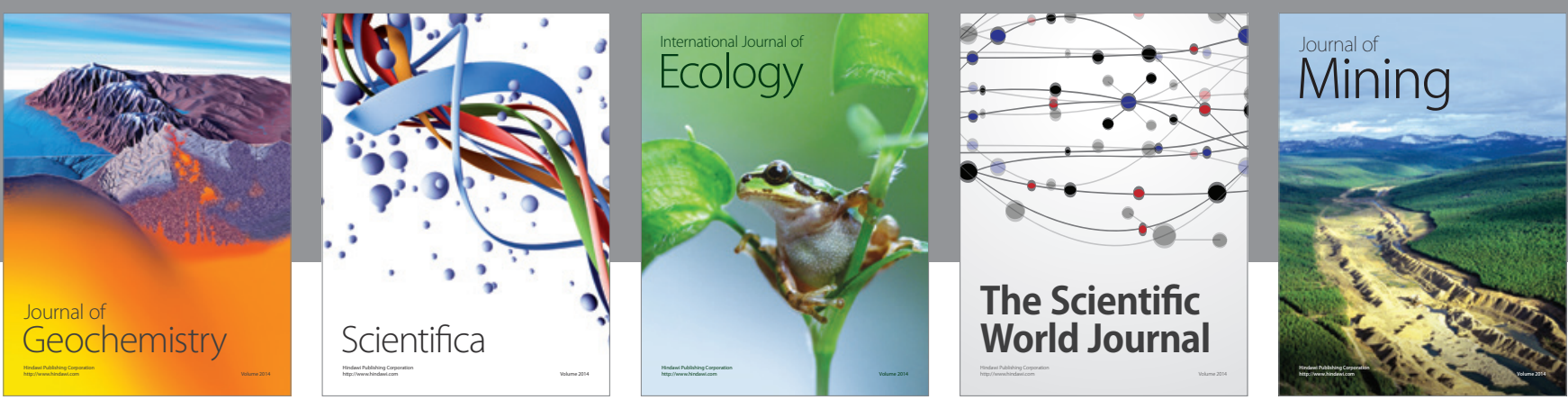

The Scientific World Journal
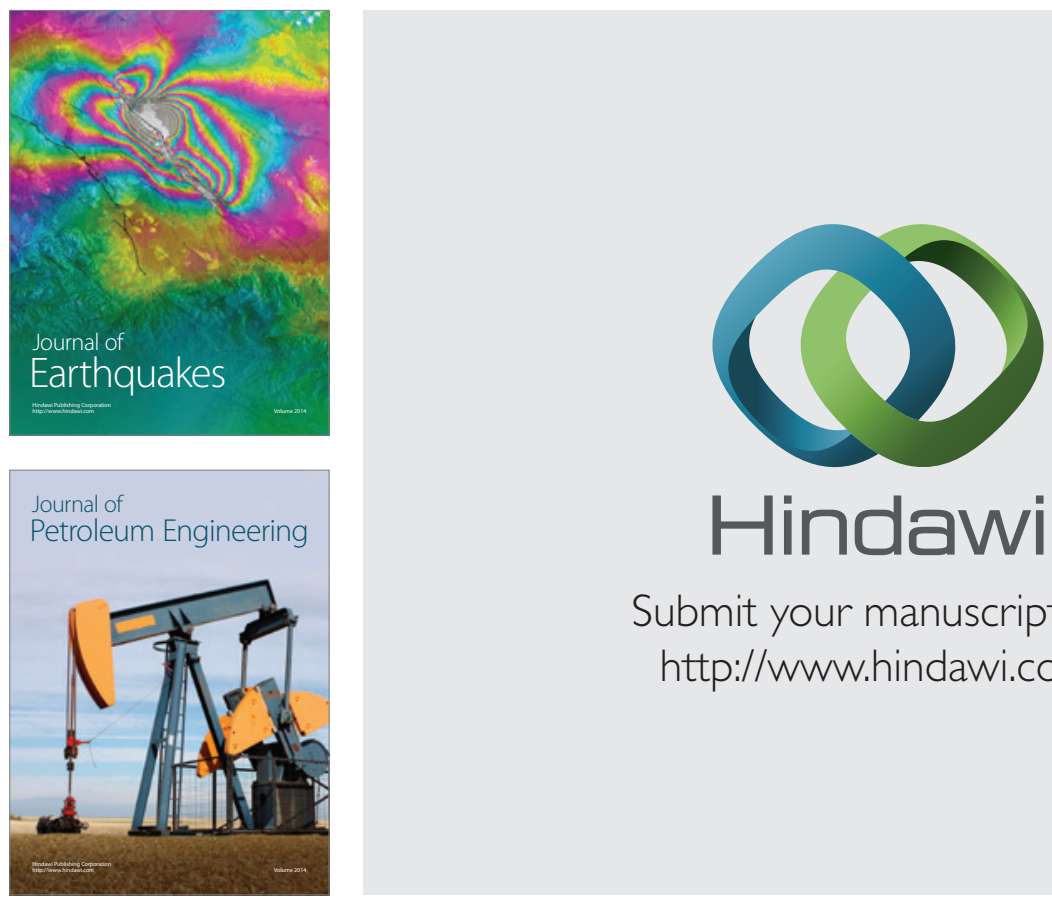

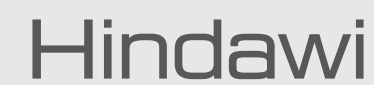

Submit your manuscripts at

http://www.hindawi.com
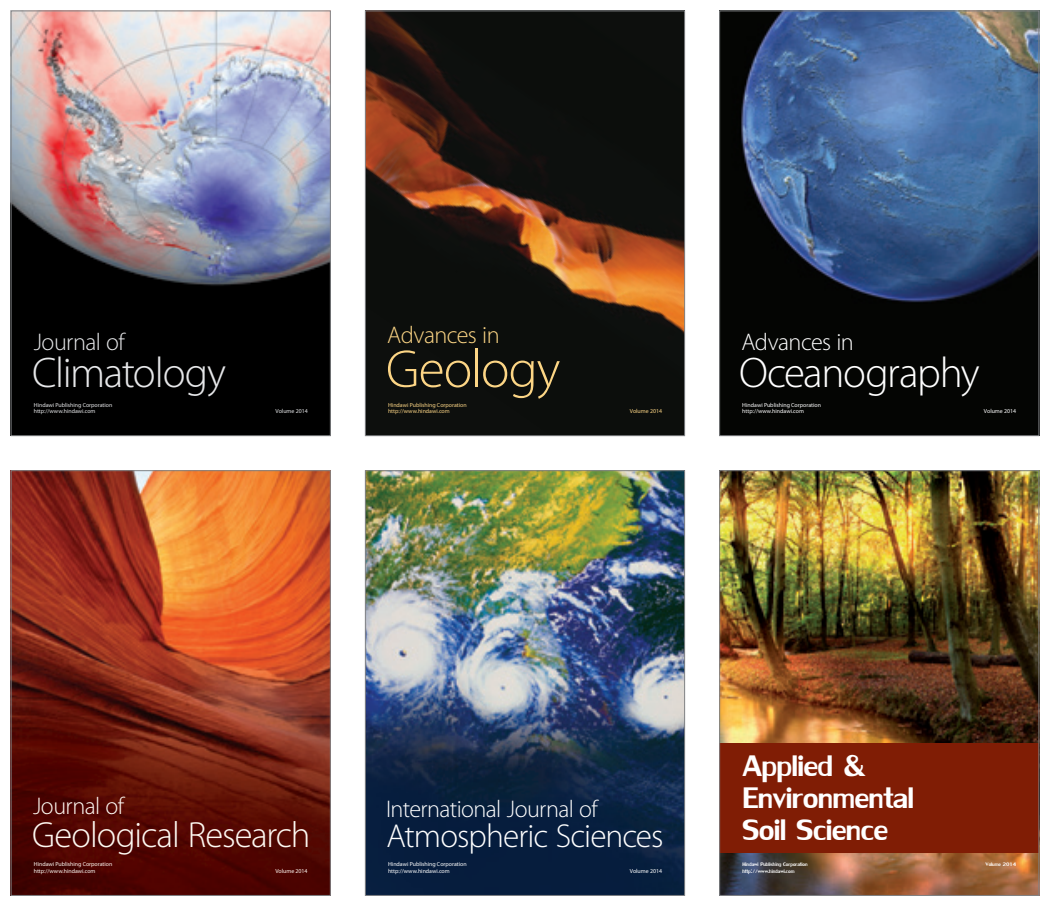
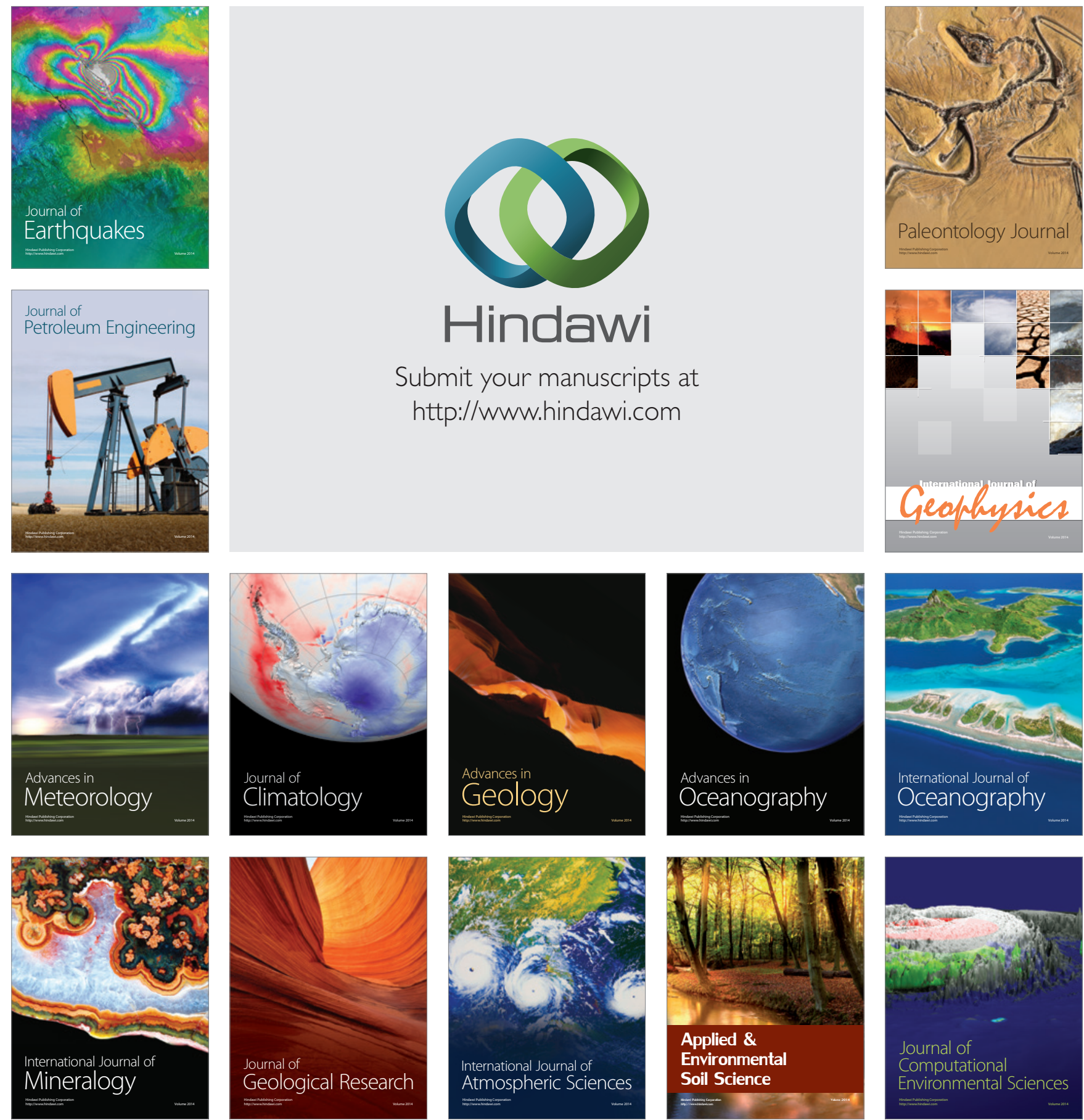